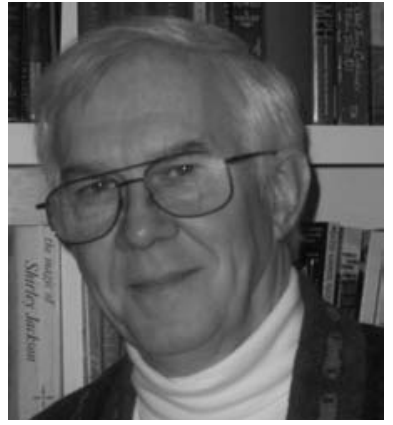

\section{The First Scientific Paper}

In his short biography of Isaac Newton, ${ }^{*}$ James Gleick comments in an endnote (Note 9, p. 214) that a letter from Newton sent to Henry Oldenburg on February 6, 1672, was "the first major scientific work published in a journal." It was, in effect, the beginning of a concept that continues today. Optical Engineering is an extension of Newton's letter.

The letter did not have a title, but Oldenburg, the Secretary of the Royal Society of London, provided a description of the letter in the contents to Volume 6, Numb. 80 of the Society's Philosophical Transactions, which was published less than two weeks later on February 19, 1672. Talk about rapid publication! In the list of contents, Oldenburg referred to the letter as "his New Theory about Light and Colors...."

Along with Newton's letter, that issue of Phil. Trans. contained notices on "A description of the East Indian Coast, Malabar, Coromandel, Ceylon, etc.," a discussion in Latin, "Institutio Philosophæ," with Descartes as second author, and "An Essay to the Advancement of $\mathrm{Mu}$ sick." According to Glieck (Note 24, p. 213), Phil. Trans., begun in 1665 , was nearly the first scientific journal. The Academia del Cimento began publishing a journal eight years earlier in 1657, but stopped in 1667. In addition, the French Journal des Savans began publishing just two months before Phil. Trans. Newton's letter appeared in issue "Numb. 80." Obviously, there had been numerous submissions to these scientific journals before this letter. Why was this one so different from everything that came before? And what made it a model for everything that would come after?

It is because it described an experiment. Instead of a report on the East Indian coast or an essay on music, Newton described his experimental setup, complete with figures, his observations, and his conclusions. It was, in effect, a narrative of his efforts to understand the nature of color. In the letter, which is 13 pages long in Phil. Trans., he describes, with a digression into telescopes and microscopes, the steps that led him to the conclusion that light contains the colors of the spectrum and the spectral colors cannot be changed ("imparted" is the word Newton used) by passage through a body.

The letter of describing the experiment was, in itself, an experiment. As Gleick notes, it was ...his first communication of scientific results in a form intended for publication. It was meant to persuade. He had no template for such communication, so he invented one: an autobiographical narrative, step by step, actions wedded to a sequence of reasoning. He exposed intimate feelings: his pleasure at the display of colors, his uncertainty, and then above all his surprise and wonder. (p. 82)

As with most experimental papers we write, details get cleaned up, blind alleys are not mentioned, and nagging details may get glossed over. Our experiments proceed triumphantly from start to finish.

I believe there was another influence that contributed to the form and progress of Newton's experiments and thus to the paper. This was his lifelong obsession with alchemy. In a chapter devoted to this topic (pp. 99-106), Gleick describes Newton's efforts in the field. He concludes from Newton's alchemical writings, long suppressed, that he was "...in the breadth of his knowledge and his experimentation, the peerless alchemist of Europe." (p. 99)

Alchemy probably was partly responsible for the bouts of madness that Newton suffered in later life. But the other thing that his practice of alchemy did was to force him (as we seem not to be able to convince most of our graduate students) to keep a notebook of each of his preparations and purifications. In his experiments with light, his recording was no longer confined to recipes and their results, but to measuring the distance between a prism and a screen, the sines of the angles of incidence and refraction, and aperture diameters. This, as it turned out, was the true gold. The letter was the beginning of our field of optics as a body of rules that described an important facet of nature and that provided the relationships engineers could employ to invent new devices.

Donald C. O'Shea Editor

*James Gleick, Isaac Newton, Pantheon Books, New York (2003). 